\title{
Using Blended Learning for Developing Faculty of Dar AL-Uloom First Year EFL Students' Reading Comprehension and Grammatical Competence
}

\author{
Dr. Marwa Gamal Muhammad Shehata
}

TEFL Lecturer at the Dept. of Curriculum \& Instruction Faculty of Education-Minia University

\section{Abstract:}

The purpose of the study was to investigate the use of
blended learning for developing Faculty of Dar Al-
Uloom first year EFL students' reading comprehension and grammatical competence. Fifty students were enrolled in the first year during the academic year 2018-2019 acting as one study group participated in the study. Two tests were prepared by the researcher: a pre-post reading comprehension test and a pre-post grammatical competence one. In addition, a teachers' guide was prepared by the researcher for presenting the online and face to face sessions. Having pretested students, they were taught via blended learning. After that, they were post tested. The findings showed a considerable statistical improvement favoring the post administrations of the two tests. Moreover, there was a positive correlation between students' EFL reading comprehension and grammatical competence on the post tests. Recommendations and suggestions for further research were presented.

Key words: Blended Learning- Reading ComprehensionGrammatical Competence

\section{Introduction:}

English plays a vital role in any educational system at both national and international levels. Mastering English will certainly allow students to get access to an incredible amount of information. When learning a language, learners need to learn the four basic language skills. Definitely, they are listening, speaking, reading and writing.

Reading is considered by many researchers one of the important skills that can expand students' knowledge. Kheirzadeh \& Birgani (2018) state that reading is an essential ability that is highly required for learners to be successful in 
academic learning. Reading is a complicated process including a composition of perceptual, psycholinguistic and cognitive skills.

Reading has several definitions. For instance, Kimberly (2014) presents a number of definitions for reading comprehension:

- Comprehension is a process in which information from the text and the knowledge possessed by the reader act together to construct meaning.

- Comprehension is the ability to decode printed text and recognize and understand words. Word recognition is a foundation of reading.

- Comprehension is transacting with text in order to create meaning from it.

- Comprehension is the process of constructing meaning through dynamic interaction among: (a) the reader existing knowledge; (b)the information suggested by the text being read; and (3) the context.

Van den Broek\& Espin (2012) also define reading comprehension as a complex interaction among automatic and strategic cognitive processes that enables the reader to create a mental representation of the text. In comprehending a reading text, most students usually face several problems. It happens because they usually lack certain aspects in reading comprehension. Shanahan (2013) states that there are two aspects that can influence students' comprehension in reading; they are vocabulary background and grammar complexity. It means that besides vocabulary, knowledge of grammar is also important for students to comprehend texts.Syofiadelfi (2016) elaborates that learning reading texts covers grammar knowledge in language features. It means while reading the texts, students should also be taught about grammar and language features that are related to the texts so that students are expected to be able to comprehend the texts. For example, in learning to recount the text, students are taught about simple past tense and past continuous tense in advance so that they would know that the situation happened in the past. 
Teaching grammar is viewed as a fundamental block to use language. Success of foreign language learning mainly depends on the correct manipulation of grammar; since the latter is the motor of any language. In this respect, Akbari (2014) points out that that L2 learners usually face some comprehension problems resulting from lack or insufficiency of grammatical knowledge such as; recognizing and understanding different kinds of phrases and determining their head noun, recognizing and understanding different clauses and determining their grammatical function, recognizing the main sentence in a complex sentence and consequently failing to recognize the main verb of the sentence...etc.

Grammatical competence has been defined by Cook (2008) as the ability to recognize and produce the distinctive grammatical structures of a language and to use them effectively in communication. The term was used by Chomosky in the 1960s and refers to the implicit knowledge of structural regularities of language in the mind and the ability to recognize and produce these distinctive grammatical structures

Learning grammar unfortunately is not an enjoyable or easy task for most students to handle and teachers are even bored with their constant complaints about problems that they have in learning and applying what they have learnt to their speaking and writing. In addition, conventional classrooms, nowadays, are no longer convenient for teaching as technology has invaded all aspects of our life. Effective instructors should link technology to their classrooms as technology has been found that it is a valuable source of learning. It improves different skills like collaboration, social interaction, self-direction, global awareness, digital learning, problem solving, planning, building teams, valuing diversity. These skills can prepare students for their future careers, and thereby building awareness among generations.

One of the most preferable approaches to instruction that incorporate technology inside classrooms is "Blended learning "(BL), blended leaning combines face-to-face instruction with 
online learning. Its superiority to online learning, which lacks face-to-face interaction, is evident from studies that examined both student achievement and satisfaction. Blended learning makes extensive use of learning technologies through the "blend" of physical (e.g lectures, labs, handouts and books) and virtual environments (e.g. chatting, discussions forums, e-mails, etc.) in order to supplement traditional face-to-face learning (Singh 2003; Bonk \&Graham 2006; Precel ,2009).

Yilmaz \&Orhan (2010) offer one of the most widely accepted definitions in literature by stating that BL environment is used to maximize the benefits of both face-to-face and online methods, using the web for what it does best and using class time for what it does best. Graham (2006) identifies it as one of the top ten trends to emerge in the knowledge delivery industry. In addition, Akkoyunlu\&Soylu (2008) state that blended learning focuses on optimizing achievement of learning objectives by applying the "right" learning technologies to match the "right" personal style to transfer the "right" skills to the "right" time.

To conclude, with the establishment of open universities all over the world that requires openness, flexibility and mobility and in response to the global call for integrating the modern digital innovations into the system of higher education, blended learning works best. It has proven to be an effective approach towards integrating web-based instruction into curriculum.

\section{Review of literature:}

\section{Studies Related to Blended Learning and Reading Comprehension:}

Several studies were conducted to investigate the effect of blended learning on developing reading comprehension such as Kheirzadeh \& Birgani (2018); Karkour (2016) ; Al Zumer , Rafaai , Bader Eddin \& Al-Rahman (2013); Bejat, Yamini and Bajeri (2011).

Kheirzadeh \& Birgani (2018) conducted a study in an attempt to reveal the effectiveness of blended learning platform in improving the reading comprehension performance of Iranian 
EFL students. The participants of this study were 60 EFL students at Islamic Azad University. They were divided into two intact groups; an experimental and a control group. The first step was to administer pretests of reading and the second step was to implement the treatments. During the 10 ninety minute sessions of the study, the experimental group received reading passages of the Selected Readings book. They were also required to use the website nicenet.com at home. The control group, received regular instruction. After post testing both groups, the findings showed that blended learning had a positive effect on reading comprehension.Karkour (2016) aimed at describing a blended model used in Egyptian schools when teaching EFL reading classes. His study was divided into three parts. The first part outlined the Egyptian context and described the target learners. The second part described the suggested learning model which was based on Text Manipulation software and provided a rationale for each component of this model followed by a discussion of some practical steps for designing the blended learning model. The third part described the online courseware as a basic part of the model. The researcher concluded that every context could have its unique design according to the challenges, the settings and students' needs. He suggested a model for the Egyptian context that combine the following:(1)Reading a text in the class, (2) Doing TM at home about the same topic (3) Posting on a forum and using chat and finally (4)Coming back to the class to complete a discussion about the text and the tasks they done at home.

Al Zumer, Rafaai, Bader Eddin \& AL-Rahman (2013) examined EFL students' perception of a Blended Learning Environment. The participants included 160 male students from the department of English Faculty of Languages and Translation at King Khaled University in Saudi Arabia. Results showed the positive influence on students' reading skills and vocabulary. In addition, students developed their computer and internet skills.

Behjat, Yamini and Bajeri (2011) investigated the effect of Blended Learning on reading comprehension. The control group 
students were requested to read printed texts outside the class whereas the experimental group students were asked to visit a weblog after class to find their reading assignments. The researchers reported that reading materials on e-tool like wikis encouraged reading as they had links and were editable, and learners could access them by just clicking on the underlined term or phrase to enter a new webpage, thus they had access to more reading resources. They concluded that blended learning encouraged learners' autonomy to read more materials independent of what presented in the classroom.

\section{Studies related to Blended leaning and Grammar:}

To the researcher's knowledge only two studies were conducted in this respect. Qinndah (2018) conducted a study with the aim of investigating the impact of blended learning on English as a Foreign Language students' usage of grammar in context. A group of tenth graders participated in the study. Preposttests and an interview were used as instruments for the data collection. The results revealed that blended learning has a positive effect on students' achievement in grammar instruction as the achievement of the experimental group surpassed the control one.

Aslani and Tabrizi (2015) investigated the effects of blended learning and multimedia software on EFL students' grammar learning. Eighty seven EFL learners at the elementary level of language proficiency were assigned to three groups: the experimental, control, and constant groups. A grammar test was given to the students in order to have homogeneous experimental and control groups before the experiment. The experimental group received instruction through blended learning and multimedia softwares, the control group received regular instruction, and the constant group used worksheets prepared by their language school. Data were collected through a grammar post-test, a questionnaire, and classroom observations. The results showed that blended learning and multimedia softwares had positive effects on the students' grammar learning. 


\section{Studies related to Reading comprehension and Grammar:}

Shahi (2016) investigated the effect of explicit teaching of grammatical structures on enhancing reading comprehension of English for Specific Purpose (ESP) students. Participants of the study were a group of EFL university students majoring in computer engineering and IT (Information Technology). A pretest and posttest of grammar contained multiple choice; fill in the blank, substitution and written form in composition. Two groups were randomly selected as a control group and an experimental one. The experimental group was taught grammar explicitly while the control group did not receive any treatment. A quasi experimental design was utilized in the study with its treatment that lasted four months (one semester). Results revealed the superiority of the experimental group to the control one, and, in the long run, spotlighted explicit grammar instruction as a scaffolding device that can provide a fertile ground for students to improve reading comprehension.

Akbari (2014) investigated the extent to which knowledge of grammar accounts for the effectiveness in L2 reading comprehension. It was a qualitative study focusing on the various aspects of grammatical knowledge in reading comprehension. The findings revealed that as soon as learners learned how to manipulate syntactic structures in a text while reading a text, their comprehension was greatly promoted.

Chenoweth and Murday (2003) conducted a comparative study where a blended learning group had synchronous chat program using course management system WebCt. Their variables were grammatical knowledge, listening and reading comprehension, and written and oral production. Students were asked to send text chats and emails, and post on the bulletin board. Results indicated better performance of the experimental group on writing, but there was not any significance difference between the two groups on oral production, listening and reading comprehension and grammatical knowledge. 


\section{Conclusion:}

The above mentioned review of literature on the area related to blended learning, reading comprehension and grammatical competence gave the researcher knowledge and confidence in stating the hypotheses of the present study. It also revealed that few studies were conducted on the effect of blended learning of reading comprehension and grammatical competence especially in the Egyptian contexts and for those students whose major is not English. Therefore, the current study sought to fill in this gap. The current study was similar to the previous studies as it focused on the same variables but it tried to investigate them in different context. It attempted to investigate the effect of blended learning on developing Faculty of Dar Al-Uloom EFL students' reading comprehension and grammatical competence and tried to find out the correlation between the two variables. The current study offered a teachers' guide to point out and manifest to EFL instructors how they could skillfully use the online sessions with in-class activities applied in face to face sessions.

\section{Context of the problem:}

Based on the results of the English language admission test that was administered to students before being enrolled in the Faculty of Dar Al-Uloom at Minia university at the blended learning program (a newly established program by Minia University), it could be concluded that most students' scores were low. Moreover, conducting informal interviews with EFL Staff members who previously taught the English course there revealed that students found difficulty in learning English and they needed more exposure to language learning as two hours a week was not enough for increasing their language proficiency. Therefore, the researcher aimed to investigate the use of Blended Learning in developing EFL students' comprehension and grammatical competence as Blended learning has increased broadly over the past few decades. Blended learning is used intentionally in this study as a means of instruction to develop 
EFL students' reading comprehension and grammatical competence for two main reasons:

- The first reason is that the participants of the study were nonmajors; they were not specialized in English language and consequently they had little knowledge and acquaintance of English language. The researcher aimed to develop EFL students' reading comprehension first as many language learners regard reading as the first skill that should be mastered among the language skills (Grabe, 2001; Jalilifar, Hayati \&Saki, 2002; Richard\& Renandya,2008) in addition to the development of their grammatical competence as it is considered a vital language component.

- The second reason is that blended learning can allow learners to increase their exposure to English language as it has several features as Huang , Zhou and Wang (2006) and Al Fiky (2011) highlight that it is student centered, promotes flexibility of giving learning resources, caters for students' learning styles, learning proficiency and learning ability, develops students' self-regulations, can widen the spaces and chances accessible for learning and maintains course management actions (e.g., communication, assessment, submission, marking and feedback).

\section{Statement of the problem:}

Based on students' low level in the English language admission test as manifested in their low scores in test and reviewing the benefits of blended learning in higher Education. The present study attempted to help such students develop their reading comprehension and grammatical competence via blended learning.

\section{Objectives of the study of the Study:}

The present study was conducted to identify the following objectives:

- The use of blended learning to develop Faculty of Dar-Al Uloom first year EFL students' reading comprehension. 
- The use of blended learning to develop Faculty of Dar-Al Uloom first year EFL students' grammatical competence.

- The correlation between EFL students' reading comprehension scores and theirs on grammatical competence.

Questions of the Study: The current study was an attempt to answer the following questions:

- How would blended learning develop Faculty of Dar Al-Uluum first year EFL students' Reading Comprehension?

- How would blended learning develop Faculty of Dar Al-Uluum first year EFL students' grammatical competence?

- How would the correlation be between EFL students' reading comprehension and their grammatical competence?

Hypotheses of the Study: In the light of the literature review the following hypotheses were tested:

- There would be a statistically significant difference between the study group's mean scores of reading comprehension preposttest (favoring the post testing)

- There would be a statistically significant difference between the study group's mean scores of grammatical competence pre-posttest (favoring the post testing) .

- There would be a positive correlation between the study group's scores in grammatical competence and theirs in reading comprehension.

\section{Significance of the Study: The importance of the current study emerged from the following points:}

- The present study tried to fill in a gap in the review of literature about studies that dealt with using blended learning in developing students' reading comprehension and grammatical competence.

- It offered a teacher's guide for presenting the online and face to face sessions.

- The study encouraged students to learn by doing things actively instead of being too dependent upon their instructors. 
- It helped students to strengthen their linguistic skills by positively affecting their learning attitude and by helping them build learning strategies and promote their self-confidence.

- It used info graphics and YouTube videos for providing students' with explicit and clear explanation of grammatical structures. Moreover, an audio script for each reading text was available.

- It helped teachers and faculty members use the infographics and YouTube videos while teaching reading comprehension and grammar to secondary and college students.

\section{Delimitations of the Study: The Study was delimited to:}

- Faculty of Dar Al-Uloom first year students enrolled at the Blended Learning Center at Minia University as students had to study for the first time via blended learning. The researcher prepared online sessions in cooperation with the E-Learning Center and taught face to face sessions at the Faculty of Dar-Al Uloom- Minia University.

- The researcher administered a questionnaire on seven EFL and TEFL staff members to determine the most important reading comprehension skills that should be emphasized in the sessions. They suggested the following:

1. Identifying the main idea, important facts and supporting details.

2. Distinguishing between facts and opinions

3. Making inferences and predictions.

4. Using contextual clues to infer meanings

5. Identifying the author's opinion

6. Skimming the reading text to get the general idea

7. Scanning the reading text to search for details

8. paraphrasing information

9. Drawing conclusions

10. Summarizing

- The researcher administered a questionnaire on seven EFL and TEFL staff members to determine the most important grammatical topics to be introduced to the target participants. They suggested the following topics:

11. Tenses 
12. Conditional Structures

13. Comparative and Superlative Adjectives

14. Nouns (Countable , Uncountable, Plural Nouns)

15. Passive Voice

16. Adjectives and Adverb

17. Prepositions

18. Whatever-Whenever-Wherever-Whichever-Whoever

19. Reported (Indirect) Speech

20. Linking Words

21. Commonly Confusing Words

- The use of MOODLE as one of the most advanced content management systems. It was used to organize the online sessions available on elearning.minia.edu.eg as it had several facilities; it was free and was considered a proper content management system.

1. The implementation of the study was in the first term of the academic year 2018-2019.

\section{Definitions of Terms: Blended Learning (BL)}

Blended learning is operationally defined in the current study as the use of the online sessions available at elearning.minia.edu.eg with the face to face sessions held at Faculty of Dar-AlUloom, Minia University.

\section{Grammatical Competence:}

The researcher operationally defined grammatical competence in her study as students' ability to construct correct sentences, monitor grammatical errors, pass judgments about right and wrong linguistic forms, and to perform language testing tasks.

\section{Reading Comprehension:}

The researcher operationally defined reading comprehension as the students' ability to construct meaning through interaction and involvement with the written text.

\section{Method: Research Design:}

The researcher used the quasi- experimental design as it is suitable for the nature of the present study. The researcher chose 
the one group pretest posttest design to determine the effect of the treatment or intervention on the study group.

\section{Participants:}

Fifty students enrolled in the blended Learning program Faculty of Dar Al-Uloom- Minia University participated in the study.

\section{Duration of the Study:}

The study was conducted at the start of the first term of the academic year 2018- 2019 at the Faculty of Dar Al-Uloom - Minia University. The course was taught 2 hours per week; 12 hours were devoted for online learning and 12 others for face to face sessions.

\section{Instruments and Materials:}

The researcher developed a reading comprehension test, a grammatical competence test and a teacher's guide.

\section{The Reading Comprehension Test (Prepared by the researcher):}

- Test Objective:The test was designed to measure the students' entry level before experimentation as (a pre-test) and to investigate the effect of blended learning on developing students' reading comprehension as (a post-test).

- Test Construction:

1. The test consisted of five passages, each passage composed of ten questions to test students' reading comprehension.

2. A table of specification was designed by the researcher to guarantee that the test covered the objectives.

- Validity of the Reading comprehension Test:

1. Content Validity: The content validity of the reading comprehension test was decided by submitting it to six TEFL jury members to decide the appropriateness of the test items to the target participants and the linguistic stating of the test items. 
2. Pearson Correlation formula was used to determine the internal consistency of the test items. As seen in table (1), the results showed that the value of these items was suitable and highly consistent and valid for conducting the study as they ranged from (0.65 to 0.94).

Table (1)The Internal Consistency of the Reading comprehension

\section{Test}

\begin{tabular}{|c|c|c|c|}
\hline No. & R & No. & R \\
\hline 1 & ${ }^{*} 0.88$ & $\mathbf{2 6}$ & ${ }^{*} 0.82$ \\
\hline $\mathbf{2}$ & ${ }^{*} 0.82$ & $\mathbf{2 7}$ & ${ }^{*} 0.85$ \\
\hline $\mathbf{3}$ & ${ }^{*} 0.86$ & $\mathbf{2 8}$ & ${ }^{*} 0.73$ \\
\hline $\mathbf{4}$ & ${ }^{*} 0.88$ & $\mathbf{2 9}$ & ${ }^{*} 0.69$ \\
\hline $\mathbf{5}$ & ${ }^{*} 0.82$ & $\mathbf{3 0}$ & ${ }^{*} 0.87$ \\
\hline $\mathbf{6}$ & ${ }^{*} 0.86$ & $\mathbf{3 1}$ & ${ }^{*} 0.73$ \\
\hline $\mathbf{7}$ & ${ }^{*} 0.75$ & $\mathbf{3 2}$ & ${ }^{*} 0.65$ \\
\hline $\mathbf{8}$ & ${ }^{*} 0.82$ & $\mathbf{3 3}$ & ${ }^{*} 0.79$ \\
\hline $\mathbf{9}$ & ${ }^{*} 0.86$ & $\mathbf{3 4}$ & ${ }^{*} 0.90$ \\
\hline $\mathbf{1 0}$ & ${ }^{*} 0.82$ & $\mathbf{3 5}$ & ${ }^{*} 0.82$ \\
\hline $\mathbf{1 1}$ & ${ }^{*} 0.86$ & $\mathbf{3 6}$ & ${ }^{*} 0.93$ \\
\hline $\mathbf{1 2}$ & ${ }^{*} 0.73$ & $\mathbf{3 7}$ & ${ }^{*} 0.90$ \\
\hline $\mathbf{1 3}$ & ${ }^{*} 0.82$ & $\mathbf{3 8}$ & ${ }^{*} 0.82$ \\
\hline $\mathbf{1 4}$ & ${ }^{*} 0.88$ & $\mathbf{3 9}$ & ${ }^{*} 0.88$ \\
\hline $\mathbf{1 5}$ & ${ }^{*} 0.82$ & $\mathbf{4 0}$ & ${ }^{*} 0.73$ \\
\hline $\mathbf{1 6}$ & ${ }^{*} 0.86$ & $\mathbf{4 1}$ & ${ }^{*} 0.88$ \\
\hline $\mathbf{1 7}$ & ${ }^{*} 0.88$ & $\mathbf{4 2}$ & ${ }^{*} 0.73$ \\
\hline $\mathbf{1 8}$ & ${ }^{*} 0.73$ & $\mathbf{4 3}$ & ${ }^{*} 0.93$ \\
\hline $\mathbf{1 9}$ & ${ }^{*} 0.82$ & $\mathbf{4 4}$ & ${ }^{*} 0.82$ \\
\hline $\mathbf{2 0}$ & ${ }^{*} 0.86$ & $\mathbf{4 5}$ & ${ }^{*} 0.70$ \\
\hline $\mathbf{2 1}$ & ${ }^{*} 0.76$ & $\mathbf{4 6}$ & ${ }^{*} 0.94$ \\
\hline $\mathbf{2 2}$ & ${ }^{*} 0.85$ & $\mathbf{4 7}$ & ${ }^{*} 0.82$ \\
\hline $\mathbf{2 3}$ & ${ }^{*} 0.73$ & $\mathbf{4 8}$ & ${ }^{*} 0.84$ \\
\hline $\mathbf{2 4}$ & ${ }^{*} 0.69$ & $\mathbf{4 9}$ & ${ }^{*} 0.88$ \\
\hline $\mathbf{2 5}$ & ${ }^{*} 0.93$ & $\mathbf{5 0}$ & ${ }^{*} 0.73$ \\
\hline
\end{tabular}

- Significant at 0.05

- D. Reliability of the Reading Comprehension Test: To establish the reliability of the test, the researcher used Alpha- Cronbach formula. As shown in table (2), the reliability coefficient was $(0.980)$ and that value had a statistical significance which proved the reliability of the test.

Table (2)The Reliability of the Reading Comprehension Test

\begin{tabular}{|l|l|l|l|l|l|}
\hline Variable & Mean & Variance & $\begin{array}{l}\text { Standard } \\
\text { Deviation }\end{array}$ & $\begin{array}{l}\text { No. of } \\
\text { Items }\end{array}$ & $\begin{array}{l}\text { Cronbach's } \\
\text { Alpha }\end{array}$ \\
\hline $\begin{array}{l}\text { Reading } \\
\text { Comprehension }\end{array}$ & $\mathbf{3 7 . 4 6 6 7}$ & $\mathbf{3 2 2 . 6 0 2}$ & $\mathbf{1 7 . 9 6 1 1 3}$ & $\mathbf{5 0}$ & $* * 0.980$ \\
\hline
\end{tabular}

- Significant at 0.05 and bound 
- Piloting the test:The test was piloted by administering it to 30 students other than those participating in intervention. Piloting the test aimed to measure validity, reliability, appropriateness to students' level and test timing. Timing the test was computed by dividing the time taken by each student divided by the whole number of students taking the test. The time of the test was two hours.

- Scoring the test: The total score of the test was fifty marks; one mark for each question.

\section{The Grammatical Competence test:}

- Test Objective: The test was designed to measure the students' entry level before experimentation as (a pre-test) and to investigate the effect of blended learning on developing students' grammatical competence as (a post-test)

- Test Construction:

3. The test consisted of fifty questions they were as follows:

4. Forty Multiple Choice Questions.

5. Ten true or false sentences.

6. A Table of specifications was designed by the researcher to guarantee that the test covered objectives.

- Validity of the Grammatical Competence Test is shown in table 1.Content Validity: The content validity of the grammatical competence test was decided by submitting it to six TEFL jury members to decide the appropriateness of the test items to the target participants and the linguistic stating of the test items.

- Pearson Correlation formula was used to determine the internal consistency of the test items. As seen in table (3), the results showed that the value of these items was suitable and highly consistent and valid for conducting the study as they ranged from (0.62 to 0.90$)$.

- Significant at 0.05

- Reliability of the Grammatical Competence Test: To establish the reliability of the test, the researcher used Alpha- Cronbach formula. As shown in table (4), the reliability coefficient was (0.987) and that value had a statistical significance which proved the reliability of the test. 
Table (3)The Internal Consistency of the Grammatical Competence

\begin{tabular}{|c|c|c|c|}
\hline \multicolumn{4}{|c|}{ Test } \\
\hline No. & $\mathbf{R}$ & No. & $\mathbf{R}$ \\
\hline 1 & $* 0.67$ & 26 & $*^{*} 0.62$ \\
\hline 2 & $* 0.83$ & 27 & $* 0.62$ \\
\hline 3 & $* 0.90$ & 28 & $* 0.67$ \\
\hline 4 & $* 0.77$ & 29 & $* 0.83$ \\
\hline 5 & $* 0.67$ & 30 & $* 0.90$ \\
\hline 6 & $* 0.83$ & 31 & $* 0.77$ \\
\hline 7 & $* 0.90$ & 32 & $* 0.80$ \\
\hline 8 & $* 0.77$ & 33 & $*_{0.67}$ \\
\hline 9 & *0.80 & 34 & $* 0.83$ \\
\hline 10 & $* 0.75$ & 35 & ${ }^{*} 0.90$ \\
\hline 11 & $* 0.84$ & 36 & $* 0.77$ \\
\hline 12 & $* 0.90$ & 37 & $* 0.80$ \\
\hline 13 & $* 0.77$ & 38 & $* 0.67$ \\
\hline 14 & $* 0.67$ & 39 & $* 0.83$ \\
\hline 15 & $* 0.83$ & 40 & $* 0.90$ \\
\hline 16 & $* 0.90$ & 41 & $* 0.75$ \\
\hline 17 & $* 0.77$ & 42 & $*_{0.67}$ \\
\hline 18 & $* 0.67$ & 43 & $* 0.83$ \\
\hline 19 & $* 0.71$ & 44 & $* 0.90$ \\
\hline 20 & $* 0.70$ & 45 & $* 0.77$ \\
\hline 21 & $* 0.67$ & 46 & $* 0.67$ \\
\hline 22 & *0.83 & 47 & $* 0.83$ \\
\hline 23 & *0.90 & 48 & $* 0.90$ \\
\hline 24 & *0.77 & 49 & $* 0.77$ \\
\hline 25 & $* 0.80$ & 50 & $* 0.63$ \\
\hline
\end{tabular}

Table ( 4 )Alpha's Reliability of the Grammatical Competence Test

\begin{tabular}{|l|l|l|l|l|l|}
\hline Variable & Mean & Variance & $\begin{array}{l}\text { Standard } \\
\text { Deviation }\end{array}$ & $\begin{array}{l}\text { No. of } \\
\text { Items }\end{array}$ & $\begin{array}{l}\text { Cronbach's } \\
\text { Alpha }\end{array}$ \\
\hline $\begin{array}{l}\text { Grammatical } \\
\text { Competence }\end{array}$ & $\mathbf{3 7 . 7 0 0 0}$ & 290.493 & $\mathbf{1 7 . 0 4 3 8 6}$ & 50 & $* * 987$ \\
\hline
\end{tabular}

* Significant at 0.05 and bound

- Piloting the test:The test was piloted by administering it to 30 students other than those participating in intervention. Piloting the test aimed to measure validity, reliability, appropriateness to students' level and test timing. Timing the test was computed by dividing the time taken by each student divided by the whole number of students taking the test. The time of the test was two hours.

- Scoring the test: The total score of the test was fifty marks; one mark for each question. 


\section{The Main features of the Teacher's Guide:}

Participants in the current study had to get access to a number of online sessions carefully prepared by the researcher availableat:http://elearning.minia.edu.eg/moodle/course/view. php?id=22 Participants had face to face sessions presented by the researcher at the Faculty of Dar Al Uloom to make sure that students had completely understood the information provided in the online sessions

\section{The Online sessions were divided in two parts:} Objectives of part one (Reading Comprehension): Participants were expected to:

- make inferences and predictions based on comprehension of the text.

- make use of contextual clues to infer meanings of unfamiliar words from context.

- identify author's opinion

- distinguish main ideas from specific details

- distinguish facts from opinion

- skim the text to get the general idea.

- scan parts of the text for getting details.

- develop reading speed

- draw conclusions

- build up academic vocabulary

- paraphrase information in the text

- discuss the content of the text orally and in writing

- utilize digital literacy tools to develop reading and vocabulary skills.

\section{Objectives of Part Two (Grammar): Participants were expected to:}

- identify the various tenses in English language.

- use 'conditional structures' appropriately.

- use 'comparative and superlative' adjectives appropriately

- use 'countable and uncountable' nouns appropriately.

- use 'passive voice' appropriately.

- use 'adjectives' and 'adverbs' accurately in s

- use 'prepositions' precisely.

- use 'relative pronouns' in constructing sentences.

- use 'reported speech' accurately when constructing sentences 
- use 'linking words 'in connecting sentences.

- identify the most commonly confusing words

\section{Content:}

- Part one: It was devoted to the development of students' reading comprehension; it was composed of three units - each unit consisted of five lessons- through which students could develop their reading comprehension skills. It provided them with a number of reading texts on more challengeable topics and thought provoking questions. There were reading comprehension exercises for the purpose of checking their reading comprehension. The units were as follow:

1. Unit One: Reading for Details

2. Unit Two: Read \& Complete

3. Unit Three: Reading \& Vocabulary

- Part two: This part was concerned with the development of participants' grammatical competence through focusing on the most grammatical rules and structures in English language. In this part, participants were asked to study eleven grammatical topics. There were a number of grammatical activities, questions and quizzes, which participants' had to answer online. These lessons were:

1. Tenses

2. Conditional Structures

3. Comparative and Superlative Adjectives

4. Nouns (Countable, Uncountable, Plural Nouns)

5. Passive Voice

6. Adjectives and Adverb

7. Prepositions

8. Whatever-Whenever-Wherever-Whichever-Whoever

9. Reported (Indirect) Speech

10. Linking Words

11. Commonly Confusing Words

\section{The Role of the Instructor:}

- In Online Sessions: The instructor monitored students; entrance onto the online sessions, checked any online assignments and provided learners with the any needed feedback 
- In the Face to Face Sessions: The instructor provided students with clear illustrations to any vague and unclear grammatical rule. In the reading sessions, she modeled loudly how to understand and guess the meaning of a difficult word from the contextual clues. In class activities were also implemented to check for students understanding

\section{The Role of the participants:}

- In Online Sessions: The participants' main role in online sessions was to work on their pace, participating in online activities and achieving their learning autonomy. All participants had an orientation session to get access to the online sessions. Each participant received a user name and a password. They had to answer the required quizzes and assignments provided after each session.

- In the Face to Face sessions: The participants' main role in the face to face sessions was to participate positively in in-class activities.

\section{Pre-testing:}

The researcher noticed at the beginning of the course that participants were reluctant to participate in face to face sessions and their level in English was low and this could be obviously seen in their performance in the pre-testing of both reading comprehension and grammatical competence (See Tables 5 and 6). In addition, they had also little difficulty to get access to the online sessions. The E-learning center provided two orientation sessions to make sure that each participant was able to use his or her user name and password to get access to the material and can easily reach to each part provided.

\section{Experimentation:}

Participants had to get access to the online sessions available at elearning.minia.edu.eg. These sessions were carefully prepared by the researcher to develop participants' reading comprehension and grammatical competence. For the participants, the novelty of the experience was unlike anything they had practiced before. This type of learning was new to many of the participants. Participants had to get access to fifteen 
reading online sessions and eleven grammatical ones. One by one, students were asked to get access to both parts; reading comprehension and grammar. Throughout the sessions participants were trained to utilize digital literacy tools to develop reading and vocabulary skills, make inferences and predictions based on comprehension of the text, make use of contextual clues to infer the meanings of unfamiliar words from context, identify author's opinion, distinguish main ideas from specific details, distinguish facts from opinion, skim the text to get the general idea, Scan parts of the text for getting details, expand their knowledge of vocabulary, paraphrase information in the text and discuss the content of text. In addition, participants had to attend face to face sessions at the Faculty of Dar- Al Uloom. They were involved in a number of in-class activities that supported and reinforced their learning.

\section{Post-testing:}

At the end of experimentation, students were post tested using the reading comprehension and grammatical competence tests. Data were treated statistically and the findings are dealt within the following section.

\section{Findings: Testing Hypothesis one:}

- Hypothesis 1 : predicted that there would be a statistically significant difference between the study group's mean scores of reading comprehension pre-posttest (favoring the post testing). Statistical analysis shown in table (5) indicated that this hypothesis was accepted as participants' post testing exceeded their pre testing and the't' value was (31.43) and this value was significant at 0.01

Table ( 5 )Means, Standard Deviation, $t$-Value of Difference between Mean Scores Obtained by the Study Group's Pre-Post Testing on the Reading Comprehension Test

\begin{tabular}{|c|c|c|c|c|c|c|c|c|}
\hline \multicolumn{2}{|c|}{ Variable } & Mean & No & Mean & $\begin{array}{c}\text { Std. } \\
\text { Deviation }\end{array}$ & 't' value & D.F & $\begin{array}{c}\text { Sig.(2- } \\
\text { tailed) }\end{array}$ \\
\hline \multirow{2}{*}{ Reading } & Pre & 19.88 & 50 & 20.88 & 4.70 & $* * 31.43$ & 49 & 0.000 \\
\cline { 2 - 9 } & Post & 40.76 & 50 & & & & & \\
\hline
\end{tabular}

- Significant at (0.01) level 


\section{Testing Hypothesis Two:}

- Hypothesis 2 predicted that there would be a statistically significant difference between the study group's mean scores of grammatical competence pre-posttest (favoring the post testing). Statistical analysis showed that this hypothesis was acceptable as ' $t$ ' value reached (38.87) and this value was significant at 0.01

Table (6)Means, Standard Deviation, $t$-Value of Difference between Mean Scores Obtained by the Study Group's Pre-Post

Testing on the Grammatical Competence Test

\begin{tabular}{|c|c|c|c|c|c|c|c|c|}
\hline \multicolumn{2}{|c|}{ Variable } & Mean & No & Mean & $\begin{array}{c}\text { Std. } \\
\text { Deviation }\end{array}$ & 't' value & D.F & $\begin{array}{c}\text { Sig.(2- } \\
\text { tailed) }\end{array}$ \\
\hline $\begin{array}{l}\text { Grammatical } \\
\text { Competence }\end{array}$ & Pre & 20.6600 & 50 & 21.04 & 3.82 & $* * 38.87$ & 49 & 0.000 \\
\cline { 2 - 9 } & Post & 40.76 & 50 & & & & & \\
\hline
\end{tabular}

- Significant at (0.01) level

\section{Testing hypothesis Three:}

- Hypothesis 3: predicted that there would be a positive correlation between the study group's scores in grammatical competence and theirs in EFL reading comprehension. Statistical analysis showed that this hypothesis was accepted as Pearson Correlation was (0.717) and this value indicated that there was a strong positive correlation between students' reading comprehension and grammatical competence.

Table (7)Pearson Correlation between the Study groups' scores in Grammatical Competence and theirs in EFL Reading Comprehension

\begin{tabular}{|c|c|c|}
\hline \multirow{2}{*}{ Variable } & Reading Comprehension \\
\hline \multirow{3}{*}{$\begin{array}{c}\text { Grammatical } \\
\text { Competence }\end{array}$} & Pearson Correlation & $0.717^{* *}$ \\
\cline { 2 - 3 } & Sig. (2-tailed) & 0.000 \\
\cline { 2 - 3 } & $\mathrm{N}$ & $\mathbf{5 0}$ \\
\hline
\end{tabular}

- Correlation is significant at (0.01) level

\section{Discussion:}

This study was a quasi-experimental field study conducted to investigate the effect of using blended learning on developing Faculty of Dar Al-Uluum first Year EFL students' reading comprehension and grammatical competence. Students who were enrolled at the blended learning Center -which was previously known as Open Education Center - studying at Faculty of Dar Al -Uloom in the academic 2018- 2019 year participated in 
the study. The number of students who were pre-post tested in reading comprehension and grammatical competence tests was fifty after excluding the dropouts.

The participants' reading comprehension consistently improved as well as their grammatical competence. One explanation for this may be the well- established online sessions and the varied and interested activities implemented in the face to face sessions. Students responded interestingly to the instructor and their classmates. In addition, participants showed positive attitudes towards the blended sessions, they pointed out that it helped them to retain what they learned. Also, it gave them feedback and improved their pronunciation and attitude towards learning English. Participants as well as the instructor found the experiment useful, available and considered it a new style of learning. In online sessions participants had to practice the reading passages and watch YouTube videos in each lesson to get clear and explicit illustration to the assigned grammatical rule through different tasks such as filling in the blanks, cloze testing, answering comprehension questions, online quizzes and story finishing. Moreover, participants were asked to answer general assignments and the instructor had to check their assignments and provide them with feedback. In face to face sessions, the instructor used different types of activities that helped participants to develop their reading comprehension such as 'information gap activities', 'turn-taking: asking and answering questions', 'memory challenge' and 'writing summaries'. Thus the current study emphasized the positive impact of using blended learning in developing participants' reading comprehension This conclusion came in accordance with the studies conducted by Kheirzadeh \& Birgani (2018), Karkour (2016), El-Zumer, Rafaai ,Bader Eddin \& Abd-Al-rahman (2013),and Behjat, yamini and Bajeri (2011) .

Moreover, blended learning in the current study proved to have a positive impact on developing participants' grammatical competence. This finding came in accordance with the studies conducted by Qinndah(2018) and Aslani (2015). During online 
sessions participants were trained to identify the various tenses in English language pointing out when to use each tense. They had sufficient acquaintance to conditional structures, comparative and superlative adjectives, countable and uncountable nouns, adjectives and adverbs, passive voice, prepositions, relative pronouns in constructing sentences, use linking words in connecting sentences and identify the most commonly confusing words. Carefully selected YouTube videos and info-graphics were used to clarify each grammatical rule and structure. In face to face session lots of activities and drills were implemented to check and foster students' comprehension of the grammatical rules presented such as "substitution drills", "transformation drills" , " finding the mistake" and information gap activities". The instructor had to use these drills and implement these activities to make sure that participants had completely understood the rule and they could apply them in their communicative situations.

Consequently, using blended learning in the current study resulted in better reading comprehension performance and higher degree in grammatical competence. This could also be obviously seen in participants' post testing of both reading comprehension and grammatical competence (see tables 5 and 6). Moreover, it reinforced participants' confidence through using technology to communicate and get feedback.

It may be concluded that the explicit instruction of grammatical structures had led to the development of participants' reading comprehension. This was due to the fact that grammatical explanation that relies on the assumption that rules learnt consciously can be converted into unconscious process of comprehension and production. Therefore, the researcher when trying to calculate the correlation between participants' reading comprehension and their grammatical competence, found that it was $(\mathrm{r}=0.7)$ and this value indicated strong positive correlation. Therefore, the current study emphasized that there was a strong positive correlation between students' reading comprehension and their grammatical 
competence. The results of the study came in accordance with Cook (2008) and Shai (2016) and Murday(2003)

\section{Implications:}

The researcher attributed the participants' improvement in the post testing of both reading comprehension and grammatical competence to a number of factors: the use of MOODLE that offered optimal opportunities for interaction between the instructor and the participant which really helped participants to develop their grammatical competence and reading comprehension and encouraged participants to practice these skills in real context. Moreover, the online sessions were carefully designed and judged, the activities included in the face to face sessions were purposely designed, the variety of assessment techniques provided whether online or in the face to face sessions, the orientation session which was held at the beginning of the course to make sure that each participant can easily and skillfully get access to the online sessions and the opportunity provided by IT center at Minia University that any student can enter the computer lab daily for free. To conclude, blended learning provided a learning milieu which really helped participants to develop their EFL reading comprehension and grammatical competence.

\section{Conclusion:}

The results of the study indicated the effectiveness of the blended learning in developing Faculty of Dar Al-Uloom First year students' EFL Reading Comprehension and Grammatical Competence. It also confirmed that there was a positive correlation between EFL students' reading comprehension and grammatical competence. Participants showed positive feelings towards the utilization of blended learning. They were of the opinion that having exposure to each session online then participating in face to face activities had greatly reinforced their learning experiences, raised their interest in learning English and helped them develop a better self-image as EFL learners. 


\section{Recommendations: In the light of the results obtained in the present study, a number of recommendations can be drawn:}

- Blended Learning should be combined in a variety of higher education courses especially the domain of language teaching.

- Developing students' attitude towards language learning should be amongst the objectives of higher Education programs.

- To create long lasting learning, providing an on-going feedback is the best way to demonstrate results.

- Adding the element of " peer and self-correction" to help learners get the chance to make up for their mistakes in reading comprehension and grammar, should be emphasized in the language courses.

- Staff members -teaching language courses - should more link theory to practice in their attempt to encourage learners to practice what they have learned.

- Adding an adaptive dimension to the Content Management System (CMS) that offers an index of difficulty for tasks, offering higher and lower tasks on the difficulty scale, so that learners become able to customize their own learning routes.

- Curriculum designers should pay more attention to the methods and techniques that encourage the involvement of learners in the act of learning.

\section{Suggestions for Further Research:}

- Investigating the impact of blended learning on developing non-majors' oral communication skills.

- Investigating the impact of blended learning on non-majors' vocabulary retention.

- Investigating the impact of blended learning on non-majors' literacy skills.

- Investigating the impact of blended learning on non-majors' self-regulation skills.

- Investigating the impact of blended learning on non-majors' attitude towards English.

- Moving ahead from blended learning to implementing mobile learning in several English Language Courses taught at the University.

- More correlative studies are still needed with reading comprehension and grammatical competence. 


\section{References:}

Akbari, Zahra (2014). The role of Grammar in Second Language Reading Comprehension: Iranian ESP Context. ProcediaSocial and Behavioral Sciences 98:122-126

Akkoya, Buket and Soylu, Meryem (2008). A Study of Student's Perceptions in a Blended Learning Environment Based on Different Learning Styles. Educational Technology \& Society, 11 (1), 183-193

Al Fiky, A. I. (2011). Blended Learning: Educational Design, Multimedia, Creative Thinking. Amman (Jordan): Dar Thaqafa for publishing and distribution.

Al-Zumor, Abul Wahed, Refaii, Ismail, Badder AEdin, Ehab \& Aziz Al-Raman , Farouq (2013). EFL Students' Perceptions of A Blended Learning Environment : Advantages, Limitations and Suggestions for Improvement. English Language Teaching , 6 (10). 95-110

Aslani, Seyyed M.\& Tabrizi, Hossein H.(2015) Teaching Grammar to Iranian EFL Learners through Blended Learning Using Multimedia Softwares. Journal of Applied Linguistics and Language Research 2(8), 76-87 Available online at www.jallr.com ISSN: 2376-760X

Behjat, F. ,Yamini, M and Bagheri. (2011). Blended Learning: A Ubiquitous Learning Environment for Reading Comprehension, International Journal of English Linguistics, 2.1, Pp-97-106

Bonk, Curtis J. and Charles, Graham R. (2006). The Handbook of Blended Learning: Global Perspectives, Local Designs. Pfeiffer John Wiley \& Sons Inc.

Chenowth, Ushida \& Murday, K (2003). Measuring student Learning in an online French Course, CALICO Journal, 20 (2), Pp285-314

Cook, V. (2008). Second Language Learning and Language Teaching (4th Ed.) New York : Arnold Publication

Grabe, Willson(2001). Reading in Second Language: Moving from theory to practice. New York: Cambridge University Press.

Graham, Carol (2006). Blended Learning Systems. Definitions, current trends and future directions. In C. Bonk \&C. Graham 
(Eds), The handbook of blended Learning: Global perspectives, local designs, San Francisco: John Wiley and Sons.

Huang, R. H., Zhou, Y. L., \& Wang, Y. (2006). Blended Learning: Theory into Practice. Beijing: Higher Education Press.

Jalifiear, A., Hayati, A.\&Saki, A.(2008). Question Strategies in testing reading comprehension: A comparative study of pre-questioning, post questioning, and in fixing. Iranian Journal of Language Studies. 2(2),115-132

Karkour, Islam (2016). A Blended Learning Model for Teaching Reading in English as a Foreign Language. Teaching English with Technology, 14 (4), Pp. 17-31, http:/ www. tewtjournal .org.

Kheirzadeh, Shiela \& Birgani, Marzieh (2018). Exploring the effectiveness of Blended Learning in Improving Reading Comprehension among Iranian EFL students. Journal of Applied Linguistics and Language Research . Volume 5, Issue 1 , pp-106-120. Available online at www.jallr.com ISSN: 2376-760X

Kimberly, Howard (2014). "DefinitionsofReading Comprehension". Available at http :www .learningunli/mite dlc.com/category/blog

Precel,Karen; Eshet-Alkalai, Yoram, \& Alberton, Yael (2009April). Pedagogical and design aspects of a blended learning course. International Review of Research in Open and Distance Learning, 10 (2), 1-16

Qindah, Suzan (2018) .The Effects of Blended Learning on EFL Students' Usage of Grammar in Context. The Eurasia Proceedings of Educational \& Social Sciences (EPESS), Vol.10 Pp: $11-22$

Richards, J.C., \& Renandya, W.A..(2008).Methodology in language teaching: An Anthology of Current Practice (5th ed.). Cambridge: Cambridge University Press.

Shahi, Medhat (2016). Improving reading comprehension of ESP Learners: Grammar Practice. International Journal of Language Learning and Applied Linguistics World. (IJLALW), 11, 135-145 
Shanahan, Timothy (2013). Grammar and Comprehension: Scaffolding Student Interpretation of Complex Sentences. Retrieved from www.shanahanonliteracy.com/2013/12/ grammar-and-comprehension-scaffolding.html (Accessed on Wednesday, February 24, 2016)

Singh, Havery (2003-November/December). Building effective learning programs. Educational Technology, 43(6),51-54

Syofiadelfi, Yuliaandri H.(2016). The Correlation between Grammar Mastery and Reading Comprehension of the Second Grade Students of SMPN 12 PEANBARU. English Study Program Language and Arts Department, Faculty of Teachers Training and Education University of Riau. Available at http: jom.unri.ac.id/index.php/JOMFKIP/article/viewFile/13349/1 2913. Retrieved on $23 / 11 / 2018$

Van den Broek, P., \& Espin, C. A. (2012). Connecting cognitive theory and assessment: Measuring individual differences in reading comprehension. School Psychology Review, 41(3), 315-325.

Yilmaz, M. Betül and Orhan , Feza (2010-January). Perspective English Teachers in Blended Learning Environment in Respect to their Learning Approaches. TOJET: The Turkish Online Journal of Educational Technology, 9 (1), 157-164. 